\title{
Ecological notes in Mediterranean halophytes. Towards an integrative approach
}

\author{
*Grigore Marius-Nicusor, **Monica Boscaiu, *Oscar Vicente \\ *Faculty of Biology, Alexandru Ioan Cuza University, Carol I, 20 A, 700505 Iasi, Romania \\ e-mail: mariusgrigorepsyche@yahoo.com \\ **Instituto Agroforestal Mediterráneo, Universitat Politècnica de València, Camino de Vera s/n, 46022 Valencia, Spain
}

\begin{abstract}
Summary. In this work we try to propose an integrative manner in which halophytes could be ecologically approached. Taking into considerations many factors related to environmental conditions, as well as corresponding adaptations in halophytes, we can obtain a good picture of interrelationships established within a typical ecosystem.
\end{abstract}

Key words: adaptations, halophytes, integrative manner, Mediterranean salt marshes zonation.

\section{Introduction}

In the Mediterranean, the halophytic communities represent two categories: those that belong to the maritime salt marshes and those that belong to the salt deserts (Chapman 1974). The maritime marshes of the Mediterranean usually lie behind coastal dunes but are subjected to salt-water inundation (Rikli 1943).

\section{Dissecting the multitude of halophytes adaptations in a salt marsh}

Glancing at the general landscape of a salt marsh in Alicante (SE Spain) (Fig. 1), it can easily be noticed the distribution of halophytes, according to their adaptations following the soil salinity gradient. Thus, the vegetation is distributed in concentric zones (belts). One of the external belt is less halophytic (including Phragmites australis), bordering one side the salt marsh; the internal belts are more halophytic. This particular arrangement is strictly controlled by salinity levels in the ecosystem, which impose different constraints to various groups of plants. The highest salinity was recorded in the center of salt marsh; here, the soil surface is often dried, and salt is deposited in a superficial layer (Fig. 1), due to an intense evapotranspiration, especially in the drought season.

Near to this central zone, only few, well adapted plants can survive in such harsh conditions. Actually, this area of salt marsh is dominated by perennial succulent euhalophytes (Sarcocornia fruticosa and Arthrocnemum macrostachyum). Their succulence is attributed to the well developed water storage tissues (Fig. 2).

Right in the central part of this salt marsh, only individual plants belonging to these taxa may be found (Fig. 3). Biochemically, Sarcocornia and Arthrocnemum seem to behave as glycine betaine accumulators, rather than proline accumulators, comparatively with other halophytes (Vicente et al., unpublished data). Actually, the entire evolution of adaptive mechanisms in halophytes from Amaranthaceae (here including and referring especially on Chenopodiaceae) are strictly related to saline environments (Grigore \& Toma 2010a; Grigore 2011).

Another belt of vegetation, located in the opposite side of salt marsh - in the upper and drier but less salinized part of it - comprises species such as: Suaeda splendens, S. vera, Salsola oppositifolia, Mesembryanthemum nodiflorum, Frankenia and Limonium species. These taxa are 


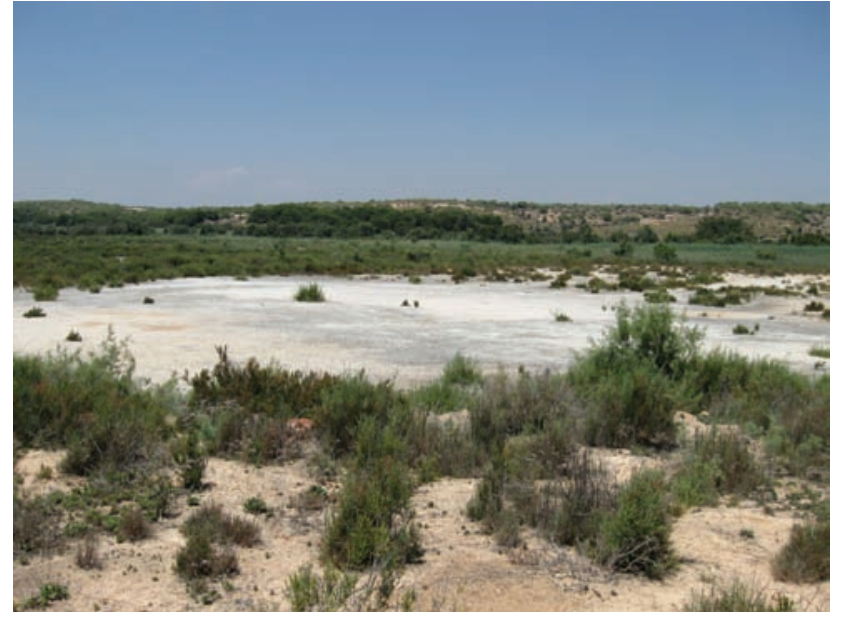

Figure 1. A salt marsh in Alicante (July of 2010)

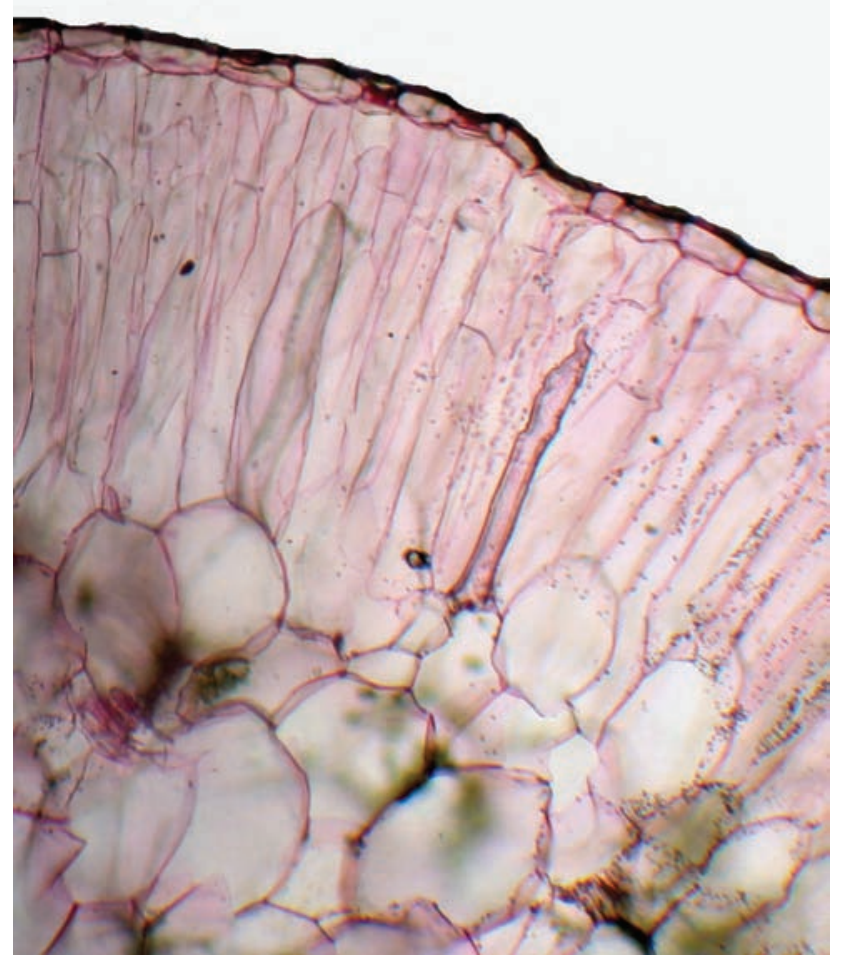

Figure 2. Water storage tissue in an articulated segment of Sarcocornia fruticosa $(\mathrm{x} 200)$

also halophytes, but less restricted to high salinity levels. Frankenia and Limonium (Fig. 4) have salt glands (Grigore \& Toma 2010b) - specialized devices involved in removal of salts from plant organs.

On the slope connecting the upper part with the lower part of salt marsh other halophytes, such as Tamarix canariensis and Centaurium spicatum may be noticed. The first

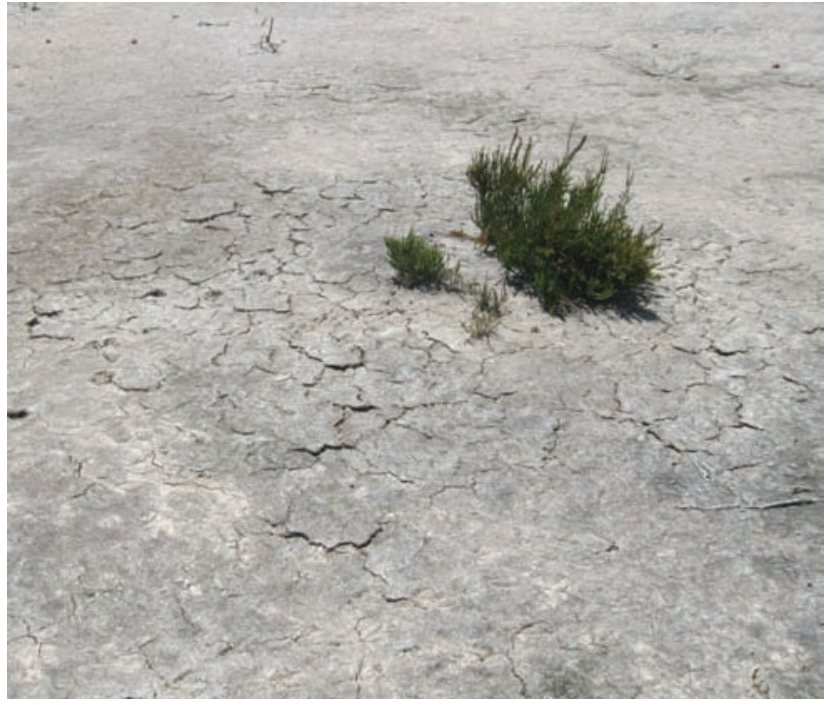

Figure 3. Individual plants of Sarcocornia fruticosa

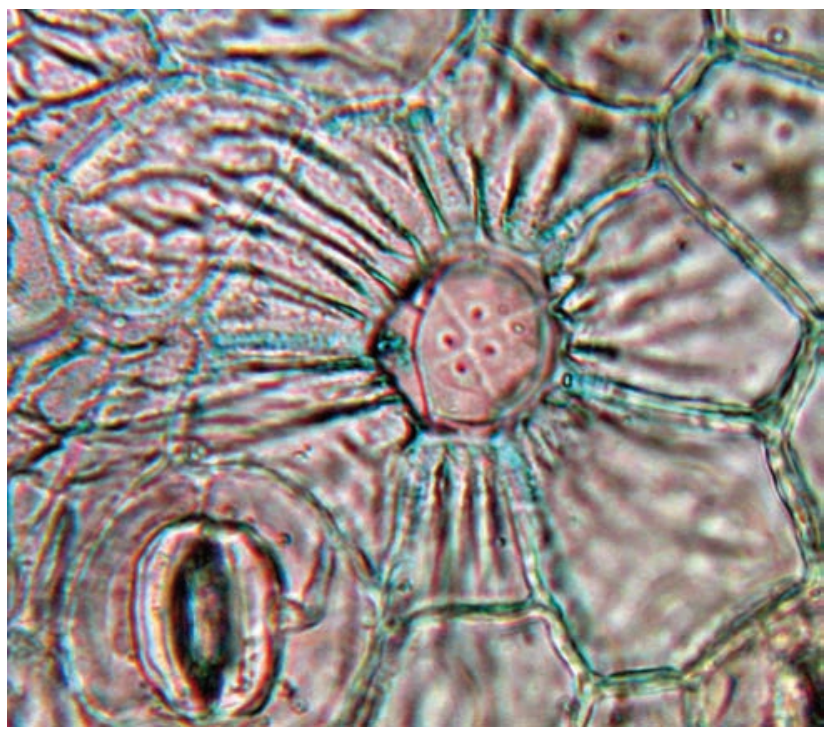

Figure 4. Salt gland in the lamina of Limonium girardianum, surface view $(\mathrm{x} 400)$

mentioned species has a very interesting ecology, being salt tolerant (also posses salt glands), phreatophyte, resistant to flooding and fires. All these features are very important and involved in some potential and even unpredictable ecological disturbances (Grigore \& Toma 2010b). In the lower part of this slope, in wet and shaded small areas vegetates Inula crithmoides, a succulent euhalophytes. 


\section{Perspectives}

Further ecological observations in the field, combined with interdisciplinary results obtained in the lab will contribute to better understanding of all interrelations established within a saline ecosystem.

\section{Aknowledgements}

Supported by grants from the Spanish Ministry of Science and Innovation, with contribution from the European Regional Development Fund (project CGL2008-00438/BOS) to O.V., and from Polytechnic University of Valencia (programme 'PAID-06-09') to M. B. M.-N. G. acknowledges the support provided by COST Action FA0901 for his stay in Valencia in the frame of a Short Term Scientific Mission, and by the Romanian POSDRU/89/1.5/S/49944 project "Developing the innovation capacity and improving the impact of research through post-doctoral programmes”.

\section{References}

Chapman V. J., 1974, Salt marshes and salt deserts of the world (second ed.), Verlag von J. Cramer, Lehre.

Grigore M.-N. \& Toma C., 2010a, Halophytes, Ecological anatomy aspects, Alexandru Ioan Cuza University Press, Iasi.

Grigore M.-N. \& Toma C., 2010b, Salt-secreting structures of Halophytes, An integrative approach, Romanian Academic Press, Bucharest.

Grigore M.-N., 2011, Evolution of anatomical adaptive strategies in halophytes, Hypotheses and scenarios, Biosystematics Berlin 2011 (21-27 February 2011), Botanic Garden and Botanical Museum Berlin-Dahlem, Freie Universität Berlin, Germany: 145.

Rikli M., 1943, Das Pflanzenkleid der Mittelmeerlander, vol. I, Bern. 